\title{
De lo crudo a lo cocinado: sobre el léxico fundamental de la culinaria en la historia del español (siglos XIII a XVII)
}

\author{
From the raw to the cooked: on the basic lexicon of culinary art \\ in the history of Spanish (13 $3^{\text {th }}$ to $17^{\text {th }}$ century)
}

\author{
Rolf Eberenz \\ Université de Lausanne \\ Rolf.Eberenz@unil.ch
}

RESUMEN: En el presente trabajo se reconstituyen las bases del vocabulario de cocina en español medieval y renacentista mediante un análisis de los verbos referentes a los procedimientos culinarios y de los nombres de las principales clases de platos cocinados. Estos nombres pertenecen a dos categorías léxicas: las nominalizaciones de verbos culinarios y los empleos metonímicos de sustantivos relativos a recipientes. La base documental consta de tratados de cocina, medicina y agricultura, y se complementa con los datos del CORDE.

Palabras clave: Lexicología histórica, semántica, lenguajes profesionales, antropología.

ABSTRACT: In this paper, we shall reconstruct the foundations of cooking vocabulary in Medieval and Renaissance Spanish by analyzing the verbs referring to culinary methods and the substantives naming the principal types of dishes. These substantives belong to two word groups: nominalizations of culinary verbs and metonymic use of designations of cooking vessels. The documentary database consists of historical cookbooks, treatises on medicine and on agriculture as well as data of the CORDE corpus.

Keywords: Historical lexicology, semantics, professional languages, anthropology. 


\section{APROXIMACIONES LINGÜÍSTICAS Y ANTROPOLÓGICAS}

La organización semántica del vocabulario español de los alimentos y de su preparación culinaria es un territorio todavía poco explorado (vid. Eberenz, 2014a), situación que contrasta con la de la pletórica investigación realizada sobre la historia social y económica de la alimentación en la Península Ibérica. En la mayoría de los estudios lexicológicos, las palabras relativas a la comida se presentan como listados alfabéticos de nombres de platos, productos, carnes y vegetales comestibles. Solo unos pocos distinguen entre denominaciones de preparados concretos y nombres de grandes conjuntos de manjares. Así, p. ej., Gerd Wotjak (1992) analiza la semántica de palabras genéricas como vianda, vituallas, víveres, legumbres, verduras, frutos/frutas, vegetales, etc., en distintas partes del mundo hispánico actual; y Arnold Rothe (1982: 192), en un estudio sobre la comida y la bebida en la obra de Quevedo, establece una serie de oposiciones fundamentales entre carne y verdura, natural y elaborado, asar y cocer, salado y dulce, etc. También se pueden mencionar, a propósito de la gastronomía catalana medieval, las propuestas de Rudolf Grewe (1979) sobre ciertas clases fundamentales de preparaciones como las denominadas con las palabras pietança, cuina, escudella, etc., que retomó más tarde Jordi Gunzberg Moll (1995) en su trabajo sobre los tratados de preservación y curación de la peste. Las mismas categorías y otras más son utilizadas por Sebastià Trias Mercant (1995) en un estudio sobre la comida en la obra de Ramón Llull a la luz de los binomios "crudo vs. cocido", "natural vs. elaborado".

Según indican estos pocos ejemplos, los alimentos se han clasificado de muchas maneras. Es más: las tipologías son casi tan numerosas como las disciplinas que se interesan por la nutrición tanto en la época moderna como desde la perspectiva histórica, esto es, la Antropología, la Sociología, la Medicina, la Gastronomía, los Estudios culturales, los Estudios literarios, etc. Ahora bien, existe en esta área temática una dicotomía profunda y elemental, que se acepta en la mayoría de dichos enfoques, entre alimentos simples (frutas, algunas hortalizas que se consumen crudas, etc.) y productos elaborados. Hoy en día esto nos parece fundamental, sensibilizados como estamos por el valor nutritivo de la fruta y la verdura frescas. No obstante, hay que tener en cuenta que en las sociedades tradicionales las viandas y los manjares eran por definición productos elaborados. Comer fruta no implicaba realmente alimentarse, y cierta corriente de la medicina medieval se mostraba francamente hostil a su consumo, lo que no impidió que en la mesa de los nobles la fruta llegara a ser muy apreciada. El consumo de vegetales crudos denotaba normalmente situaciones excepcionales, como podían ser el modo de vivir de los ermitaños, ciertas formas de penitencia o, simplemente, una gran pobreza o frugalidad (Guerreau-Jalabert, 1992: 566-567; Castro Martínez, 1996: 147-152; Mühlethaler, 1996: 18-19, 
etc.). Es cierto que, según muchos testimonios, los campesinos comían con alguna frecuencia cebollas y ajos crudos - cuyo olor motivaba el desprecio de los nobles-, pero lo hacían casi siempre en combinación con algún producto elaborado, como pan, queso, tasajo, etc. ${ }^{1}$ En líneas generales, la tópica oposición antropológica entre lo crudo y lo cocido, o entre barbarie y civilización, propuesta por Claude Lévi-Strauss (1978 [1964]: 340-347) resulta perfectamente válida para la alimentación medieval y renacentista.

Una consecuencia de este estado de cosas es que durante la época estudiada las nociones de alimentación y de culinaria se solapaban en buena parte. Pero téngase en cuenta que se trata de dos conceptos técnicos modernos, sin equivalentes exactos en la lengua antigua. El castellano medieval y clásico empleaba, en lugar de alimentación o alimento, sustantivos como (el) comer, cosa de comer, vianda, manjar y, más tarde, comida, así como otras voces más especializadas (vid. Eberenz, 2012); y lo que hoy en día llamamos gastronomía o culinaria estaba contenido en la palabra cocina, muy polisémica, aunque como actividad profesional empezó a llamarse también arte de cocinar y arte de cocina, sobre todo en los libros dedicados a este oficio.

Como todo plato es el resultado de un proceso de elaboración, uno de los caminos más prometedores para adentrarse en la lexicología de las denominaciones de preparaciones culinarias pasa por un examen detenido de los verbos referentes a tales actos. Los procedimientos principales, aunque no los únicos, son evidentemente aquellos que, mediante la aplicación de calor, permiten hacer comestibles las carnes y los vegetales. Dos destacan claramente entre los demás, el asado o exposición directa de la materia prima al fuego y la cocción o mediación de un líquido en el que se cuece el alimento. Ambas nociones, descritas por Lévi-Strauss (2004 [1965]: 11; 1968: 390-411), fueron comentadas y desarrolladas en varias ocasiones, en relación con temas peninsulares p. ej. por Pedro Gómez García (1993) y Sebastià Trias Mercant (1995). Respecto de otras lenguas, deben mencionarse los trabajos de orientación estructuralista de Adrienne Lehrer sobre los verbos referentes a las operaciones culinarias en inglés (Lehrer, 1969) así como en este idioma y en francés contrastados (Lehrer, 1972). También se han dedicado dos estudios a los verbos culinarios utilizados por Apicio en De re coquinaria: Gabriela Cruz (2012: 156-160) lo hace desde la perspectiva de la gramática sistémico-funcional de Michael Halliday, y Francisca del Mar Plaza (2012), según el modelo léxico-construccional.

\footnotetext{
${ }^{1}$ Cfr. Diego de Ávila, "Égloga ynterlocutoria”: “-Benito. Agora me quiero de grado asentar. / Saca, si tienes algo de bueno. / - Hontoya. Ajo y cebolla y pan de centeno / (¡Dios sea loado!) no puede faltar, / Y más, si quieres, te entiendo de dar / D'un gordo tasajo que tengo guardado" (Peyrebonne, 1997: 146, n. 24). Recuérdese, además, el siguiente fragmento del Quijote (I, cap. 10, p. 117): "-Aquí trayo una cebolla y un poco de queso, y no sé cuántos mendrugos de pan — dijo Sancho-, pero no son manjares que pertenecen a tan valiente caballero como vuestra merced".
} 
Así pues, la semiótica de los actos de transformación culinaria constituye el fenómeno antropológico y cognitivo más importante para el estudio del léxico alimentario. Sin embargo, hay otro elemento capital, estrechamente vinculado a la cocción, que es el tipo de recipiente en que esta se lleva a cabo. Por fin, no se deben olvidar las demás clases de procesos de elaboración, como la fermentación, el secado, la salazón, el ahumado, el confitado, etc., muchos de ellos más utilizados para la conservación de los alimentos que para hacerlos simplemente comestibles.

\section{OBJETIVOS, CORPUS Y METODOLOGÍA}

En el presente trabajo se propone pues un análisis, primero, de los principales verbos culinarios $\mathrm{y}$, segundo, de dos grandes conjuntos de platos cuyas denominaciones se basan sea en dichos verbos, sea en los nombres de las vasijas utilizadas $^{2}$. Como en cualquier estudio de lexicología histórica, el objetivo principal consiste en determinar, sobre la base de un corpus, los lexemas que por su significado forman parte de las áreas semánticas en cuestión, analizar el empleo de esas palabras en diferentes contextos, reconstituir su trayectoria histórica y, por fin, mostrar las relaciones semánticas existentes entre los términos de cada grupo. Otro punto de interés, que aquí solo se podrá comentar de forma marginal, es el diferencial entre estas parcelas del léxico de la época estudiada y los ámbitos análogos de la lengua moderna.

El período elegido se extiende de la Edad Media a las primeras décadas del siglo XVII. Esta delimitación se justifica por la relativa unidad del objeto de estudio: aunque no se puede negar que durante un lapso de tiempo tan largo el modo de alimentarse de los castellanohablantes y sus prácticas culinarias evolucionaran, estas todavía no acusan la presencia de los vegetales americanos (batatas/boniatos, chiles/pimientos, maíz, papas/patatas, tomates, etc.) ni la producción y el consumo masivo de azúcar, hechos que a partir del XVII revolucionarán la alimentación europea. Por otra parte, las primeras décadas del Seiscientos son cruciales para nuestro tema, pues durante ellas se publicaron el Tesoro de Covarrubias, observador escrupuloso de los fenómenos léxicos relativos a la alimentación (vid. Eberenz, 2014b), y dos tratados de cocina de gran interés, el Libro del arte de cozina de Domingo Hernández de Maceras (1607) y el Arte de cozina, pastelería, vizcochería, y conseruería de Francisco Martínez Mo[n]tiño (1611). Como fuentes se han vaciado estas obras y algunas más tempranas: el Arte cisoria de Enrique de Villena (1423), el anónimo Manual de mugeres (a1525), el Libro de guisados, manjares y potajes de Ruperto

\footnotetext{
${ }^{2}$ Este estudio se inscribe en un proyecto de investigación personal del autor sobre el léxico gastronómico español de la Edad Media y el Renacimiento.
} 
de Nola (1529), versión castellana del Libre del coch catalán, así como Regalo de la vida humana de Juan Vallés (a1563) y el Libro del arte de cozina de Diego Granado (1599). Vallés y Granado copian o reformulan parte de las recetas de Nola, y Granado hace lo mismo con las de la Opera del italiano Bartolomeo Scappi (1570). También se han tomado en consideración otros textos que contienen numerosas referencias a alimentos y platos, especialmente algunos tratados médicos, como Sevillana medicina de Juan de Aviñón (1381-1418), Menor daño de la medicina de Alonso de Chirino (a1429), etc., y uno de agricultura, la Obra de agricultura de Gabriel Alonso de Herrera (1513), además de otros textos. Añadamos que estas obras se han vaciado a pesar de que muchas figuran en el CORDE. La mayoría de las palabras en cuestión son voces patrimoniales que poseen de por sí un significado culinario (p. ej. cocinar) o lo adquieren a lo largo de la historia del castellano (p. ej. guisar), por lo que solo excepcionalmente nos referiremos a su etimología. Como muchas de estas voces son recurrentes en los textos, se han extraído de un gran número de ocurrencias los rasgos semánticos y, a veces, sintácticos que se revelan más importantes, según se suele hacer en la lexicografía de corpus. Estos rasgos se describen y se ejemplifican en cada caso con unos pocos ejemplos que, en la medida de lo posible, proceden de distintas obras y pertenecen a diferentes épocas. En algunas ocasiones contienen, además del lexema analizado, otros del mismo campo semántico, lo que permite contrastarlos.

Antes de entrar en materia, conviene recordar que el universo de la alimentación y su léxico muestran un fuerte parcelamiento debido a una serie de factores —en parte ya mencionados-, que son las condiciones geográficas y climáticas, las estructuras sociales, la religión y los hábitos alimenticios relacionadas con ella así como la sucesión y el contenido de las diferentes comidas de un día. Pese a estas divisiones, hay un cierto número de productos fundamentales que varían poco y pueden, por lo tanto, analizarse con facilidad.

\section{LOS VERBOS REFERENTES A LOS ACTOS CULINARIOS}

\subsection{La noción general de 'preparar [la comida]'}

Estos lexemas se caracterizan por una gran extensión semántica, al referirse de un modo general a la elaboración de la comida, abarcando pues los distintos actos necesarios para su confección, como ocurre sobre todo con adobar, guisar y cocinar.

Adobar, verbo transitivo usual desde los orígenes del idioma, poseía en la Edad Media un significado general de 'preparar, disponer, reparar' y se aplicaba a toda clase de objetos, pero desde antiguo también a la comida (cfr. DEM s. $v$. adobado y adobar): 
(1) Vayamos posar, ca la cena es adobada (c1140 Poema de Mio Cid, ed. A. Montaner; CORDE).

(2) Dizen que un omne que adobó su yantar e conbidó sus huéspedes e sus amigos (c1253 Sendebar, ed. M ${ }^{\mathrm{a}}$ J. Lacarra; CORDE).

Ahora bien, este valor general se fue perdiendo a partir del siglo XIV, quedando suplantado por el más específico de 'sazonar [un alimento] con sal, hierbas aromáticas y/o especias, etc.', que se comentará más abajo (§ 3.4.). Después de los primeros decenios del siglo XVI, ya no se encuentran ejemplos de sintagmas que atestigüen el significado primitivo, en sintagmas como, p. ej., "adobar de comer" (CORDE).

Guisar ofrece algunas analogías con la evolución de adobar. Como este, es en principio transitivo, pertenece al léxico patrimonial, significa 'preparar, disponer [un objeto]' y se emplea, además, en relación con la preparación de la comida:

(3) Querría a la obra de la tienda entrar, / en estas menudençias non querría tardar, / avemos un estonda assaz que deportar, / irsenos ha guisando demientre la yantar (1240-1250 Libro de Alexandre, ed. J. Cañas; CORDE).

(4) E quando amanesçió otro día, mandó el Rey guisar de comer a todos los de su regno (c1253 Sendebar, ed. M ${ }^{\mathrm{a}} \mathrm{J}$. Lacarra; CORDE).

Más tarde, se documenta también como verbo intransitivo, con el sentido de 'cocinar, preparar la comida':

(5) Y si esta mi agüela vivía, sabía yo más que sé, que ella me mostró guisar, que en su poder deprendí hazer fideos, empanadillas, alcuzcuzu con garbanzos, arroz entero, seco, graso, albondiguillas redondas y apretadas con culantro verde, [...] (1528 Lozana, 97).

Sin embargo, con el tiempo guisar cobra, a su vez, un significado culinario más especializado, usual hasta hoy en día y que el diccionario académico define como 'preparar los alimentos haciéndolos cocer en una salsa, después de rehogados' (DRAE 2014). Este valor es más difícil de documentar en los textos antiguos debido a la ambigüedad de la mayoría de los contextos, incluso cuando en el lugar del complemento directo se encuentra el nombre de un alimento concreto. Se puede sospechar que el valor restringido se originó primero en la nominalización guisado 'preparación culinaria' (vid. § 4.1.), en el que sí resulta fácil mostrar que se trata de un plato complejo que implica varios ingredientes, cocción en un líquido (agua, caldo, salsa, etc.) y adición de hierbas aromáticas o especias:

(6) Capítulo XV. De la tercera manera de pecar, que es buscando mill maneras e nouedades de vestiduras e de trajes, como en el comer/y beuer/ muchos guisados adobados e potajes (1477-1496 Talavera, 23). 
(7) En estas cosas de guisados \& potages: ya te he dado auiso que quando saben al humo lo puedes quitar con vna poca de leuadura agra desta manera (1529 Nola, f. 68v).

(8) Guzmán.—_No hay quien pruebe esotros guisados, estos torresnos lampreados, aquel adobado, el carnero verde, las albóndigas ni lo demás? (1599 Dialogues, 87).

Esta progresiva restricción semántica de guisado se explica sin duda por el hecho de que el arte del buen cocinero consiste sobre todo en su capacidad de confeccionar platos complejos tanto por el número de ingredientes como por los procedimientos de elaboración. Por ello no parece ninguna casualidad que el tratado de Nola se titule en su versión española Libro de guisados. Recuérdese a este propósito la graciosa afirmación de la Lozana Andaluza:

(9) Señora tía, yo quiero que vuestra merced vea lo que sé hacer, que, cuando era vivo mi señor padre, yo le guisaba guisadicos que le placían (1528 Lozana, 96).

Respecto de la pérdida del significado general de guisar 'preparar [la comida]', es difícil datarla con precisión ya que el valor restringido 'preparar unos alimentos haciéndolos cocer en una salsa' dista poco de aquel y representa el procedimiento prototípico de la actividad culinaria. De hecho, el sintagma "guisar de comer" sigue usándose hasta hoy.

Cocinar aparece hacia 1300 (CORDE), es al principio menos frecuente que, p. ej., guisar o cocer y se usa tanto con complemento directo como sin él:

(10) como enpanadas, pastiçes, asadas, albóndigas rellenas, el vientre del puerco adobado, la cabeça del puerco, tripas rellenas, morcillas, longuanizas, sopas doradas, tartras, fojaldes, panes de figos, sopresadas e otras muchas que se cuentan en el arte del cozinar (1423 Villena, 85).

(11) Yo vi tiempo que en el mundo non avía uso de tales cosas, e non sabían qué cosa era adobo de vinos nin cozinar tantos comeres, [...] (1430-1440 La Torre, 308).

(12) Offari: es cozinar. porque acostumbran cozinar menuzando lo que se cueze (1490 Palencia, f. 322r).

\subsection{Las principales operaciones culinarias que suponen aplicación de calor}

En consonancia con la tipología propuesta por los antropólogos, los verbos más emblemáticos del español en este ámbito son asar y cocer. No sorprende, pues, que ambos formen parte de los pocos lexemas de este tipo heredados del latín (ASSARE y COQUERE, respectivamente). En los textos se contraponen con 
mucha frecuencia, a veces junto a otros verbos culinarios como freír o adobar, este último en el sentido restringido de 'sazonar [un alimento] con sal, hierbas aromáticas y/o especias, etc.’, que se tratará más adelante (§ 3.4.):

(13) e combrán las carnes d'él [sc. del cabrito] assadas e non cochas nin fritas nin crudas nin en otra guisa ninguna adobadas, si non assadas en fuego (c1275 Alfonso X, General Estoria. Primera parte, ed. P. Sánchez-Prieto Borja; CORDE).

(14) truxieron mucha vianda de carneros cozidos e adovados e asados, e otrosí cavallos asados (a1412 ETamorlán, 262).

(15) tráenla [sc. la lengua del cerdo] entera salada o fresca e cocha, e después asada o en adobo, (1423 Villena, 95-96).

(16) E lo mas conuenible es comer de vna vianda avasto en cada comer sea cocho o asado o adobado (a1429 Chirino, 16).

Asar y cocer constituyen, pues, una dicotomía fundamental. Desde el punto de vista antropológico, lo asado mantiene con lo crudo una relación más estrecha que lo cocido, ya que el alimento asado - casi siempre carne o pescadoha estado en contacto directo con el fuego y representa un grado de transformación imperfecto en comparación con lo cocido, cuya elaboración se realiza con mediación del agua o de otros líquidos y suele requerir más tiempo. Así pues, el consumo de carne asada simboliza una forma de vida más primitiva y violenta que el de carne cocida, representativa de una cultura alimenticia más diferenciada (Lévi-Strauss, 2004 [1965]: 11; Gómez García, 1993). Tal contraste explicaría esa preferencia de los caballeros de la Edad Media por las viandas asadas que han subrayado los historiadores. La carne asada está, efectivamente, muy presente en la mesa de los nobles, y no es ninguna casualidad que el Arte cisoria, el primer tratado de tema culinario en lengua castellana, verse esencialmente sobre las maneras de cortarla.

Por otro lado, los tratados médicos de la Edad Media atribuyen a lo asado y a lo cocido virtudes dietéticas distintas. La carne asada se consideraba menos digesta que la cocida, pero también más seca, por lo que permitía eliminar el exceso de líquido del aparato digestivo:

(17) Sardinas frescas [...]. Y las assadas son mejores que las cozidas para enxugar el estomago de la flema insipida; (1381-1418 Sevillana medicina, 249).

(18) Las viandas de más rezio mantenimiento [...] son todas las carnes. E lo asado mantiene e esfuerça más que lo cozido puesto que es más duro de degerir (a1429 Chirino, 18-19).

(19) E si quisieren encima de lo tal cozido comer vn poco assado es bueno; a la cena, assado e poco, con los sabores e salsas susodichas (1507 Fores, 98). 
Quizás debido a estos preceptos dietéticos, en la sucesión de platos de una comida se alternan a menudo las carnes asadas y cocidas:

(20) \& dar las viandas de grado en grado: es a saber. Primeramente la fruta. \& tras ella vn potage. \& luego lo assado. despues otro potage \& lo cozido tras el potage (1529 Nola, f. 8r-v).

(21) Solían en nuestra España comer las personas ricas y los cavalleros un poco de carnero assado y cocido, [...]. Los señores y grandes comían una ave cocida y otra assada (1553 Torquemada, 331).

(22) Guzmán.—_Qué es el uso de Inglaterra? / Rodrigo.-Comer primero lo cocido que lo asado; nosotros hacemos a el revés. / Don Lorenzo.-Según reglas de medicina, primero se deben comer los manjares que son más duros de digestión. / [...] / Don Lorenzo.-Pues que sea más duro de digestión lo asado que lo cocido es cosa clara (1599 Dialogues, 83).

Asar.-Además de lo que ya se ha dicho sobre este verbo, conviene recordar que, desde el punto de vista técnico, la principal dificultad que entraña la preparación y el consumo de la carne asada es su corte y separación en piezas de fácil manejo, tema principal del Arte cisoria de Enrique de Villena y que se expone también en algunos tratados de cocina posteriores. Asimismo, se precisa a menudo que se puede asar en parrillas, en asador o sobre las brasas. Por lo demás, los tratados de cocina no suelen contener consejos sobre cómo asar la carne. Sin embargo, el simbolismo social de este procedimiento primario no implica que los caballeros medievales se alimentaran únicamente de carnes asadas, pues muy pronto la calidad de la mesa de los nobles empezó a manifestarse en la variedad de platos elaborados de distintas maneras. Así, la cultura alimenticia y el arte culinario propiamente dichos se centraban en lo cocido, no en lo asado. Aunque se asaban sobre todo distintas clases de carne y pescado, en los textos relativos a nuestro tema se encuentran testimonios de que el procedimiento se aplicaba en ocasiones también a los huevos, al queso, a frutas como los membrillos, las castañas, etc.

Cocer.-La cocción representa la actividad culinaria más importante, variada y rica en potencialidades. En primer lugar, el verbo cocer significa 'transformar [un alimento] dentro de una vasija por medio de un líquido hirviendo' (citas 13-16), siendo de notar que el alimento en cuestión puede ser de cualquier tipo, cárnico o vegetal, y que también el líquido en que se sumerge puede pertenecer a varias clases — caldo, vino, salsa, leche, etc.-, aunque el más importante es el agua. En segundo lugar, desde antiguo cocer se refiere también a la cocción del pan y de otras preparaciones de masa de harina que se realiza en el horno o sobre las brasas del hogar. Ambos procedimientos implican, pues, un espacio envolvente de modo que el denominador común de los distintos usos del verbo cocer puede describirse como 'transformar [una materia o un conjun- 
to de materias alimenticias] dentro de un objeto envolvente que proporciona calor'. Pero volvamos al significado primero de este verbo. A veces la cocción sirve también para espesar o reducir un líquido:

(23) [Arrope de granadas dulces:] espriman todo su çumo e cuéganlo en cosa vedriada o estañada o de plata, [...] con açucar que aya a dos libras de çumo vna de açucar, o de miel poco más o menos, fasta que sea bien espeso (a1429 Chirino, 160).

(24) Para cada escudilla de potaje, ocho hiemas de huebos y un poco de leche de cabras. Rebueltas muy bien las hiemas con la leche. Y después de bien rebuelto cueza hasta que espese (a1525 MMugeres, 59).

Por otro lado, el concepto de la cocción de unas piezas en un líquido puede extenderse a la noción de 'confeccionar un plato complejo, de carne o pescado y otros ingredientes como verduras, hierbas aromáticas o especias, en un líquido', que equivale prácticamente a la de guisar e ilustra la posición de cocer en el sistema de los actos culinarios:

(25) Sus lomillos [sc. del puerco] se corten a tajadas anchas e algúnt poco gruesas, tirando ayuso su cuajar, dándolo lleno de huesos menudos, con espeçias e adobos cocho (1423 Villena, 97).

Este valor se manifiesta con particular nitidez en el participio cocho/cocido, especialmente en la colocación "comer cocho/cocido":

(26) El galán ningún día / non deve comer cocido / salvando fruta y rostido / que quita malenconía (c1450 Ribera, 197).

(27) Lozana.-[a propósito del acto sexual:] ¡Cuánto había que no comía cocho! Ventura fue encontrar el hombre tan buen participio a un pasto. Este tal majadero no me falte, que yo apetito tengo dende que nascí, sin ajo y queso, que podría prestar a mis vicinas. Dormido se ha [...] (1528 Lozana, 139-140).

Por fin, hay que recordar que cocer puede funcionar también como verbo intransitivo 'hervir [un líquido]' (citas 28 y 29). En cuanto a hervir, está igualmente bien representado en los contextos culinarios. Se emplea casi siempre con valor intransitivo, sobre todo en los tratados de cocina, por lo que no lo consideramos denominación de acto culinario. Además, hervir y cocer intransitivos se usan alguna vez como sinónimos:

(28) y es menester que cueza mas: y haz que cuezga o hierua siempre: y que nunca pierda el heruor (1529 Nola, f. 35v).

(29) de suerte que hierua todo, y cuezan hasta que al maestro le pareciere: (1607 Maceras, 27). 
Freír $^{3}$.-Ya en el siglo XIII se precisan las características esenciales del procedimiento de freír, a saber, el empleo de una sartén en la que se transforma el alimento en aceite o grasa hirviendo:

(30) Tomarán la dezena parte d'un efi de flor de farina, e freír lo an con olio en sartén (c1275 Alfonso X, General Estoria. Primera parte, ed. P. SánchezPrieto Borja; CORDE).

Lo frito mantiene relaciones particulares tanto con lo asado como con lo cocido: al igual que lo asado, supone una exposición del alimento a un calor fuerte y, como lo cocido, implica el uso de una vasija y la mediación de un líquido en el proceso de elaboración, por lo que representa claramente una práctica cultural. Para incluir lo frito en la estructura antropológica de los actos culinarios, Lévi-Strauss (1968: 410) sustituyó su triángulo culinario por un tetraedro dando así cuenta del hecho de que al agua y al aire como sustancias mediadoras se añade aquí el aceite. Pero ya Covarrubias había propuesto la siguiente tipología, sumamente esclarecedora:

(31) Es verdad que freír ni es cozer en la olla ni asar en el asador, ni tostar en las parrillas ni en las brasas, sino adereçar en la sartén, echando primero algún licor, como azeite, manteca, sebo o grasa; (1611 Covarrubias, s. v. freír).

La carne y el pescado es lo que más a menudo se fríe, y Juan de Aviñón (Sevillana medicina, 215) considera que "la carne frita es liuiana de moler", es decir, de fácil digestión. Como hoy en día, el procedimiento también se aplicaba a los huevos e incluso a ciertas hortalizas como las zanahorias (vid., p. ej., Vallés, 609).

Se fríen igualmente diversos productos elaborados con masa de harina, como las tortas, las tortillas y especialmente las llamadas frutas de sartén ${ }^{4}$, entre las cuales se pueden contar, p. ej., los buñuelos:

(32) Para el dolor de xaqueca de mucho tiempo tome çumo de yerua mora e amasen con ello e con vnas tres yemas de hueuos farina de trigo çernida

\footnotetext{
${ }^{3}$ Existe también un derivado fritir: "¿Qué femencias, qué tardanças / en fritir siete buñuelos!" (a1500 Rodrigo Cota, "Copla a Pero González" [Pequeño Cancionero, ed. P. Elia]; CORDE); "Hanse de tomar los torreznos del pernil [...] y fritirlos medio fritos" (1607 Maceras, 26-27); "frío, fries, freir i fritir, rrustico" (1625 Gonzalo Correas, Arte de la lengua española castellana, ed. E. Alarcos Llorach; CORDE); "No son guevos de fritir. Dizen los labradores de lo ke no es fázil, komo freir guevos." (1627 Gonzalo Correas, Vocabulario de refranes y frases proverbiales, ed. L. Combet; CORDE). En el DCECH (s. v. freír) se menciona también fretir, del que no hemos encontrado documentación antigua.

${ }^{4}$ Uno de los primeros testimonios de la expresión, en las Poesías de Juan del Encina ("Y no menos allí davan frutas de sartén y verdes", ed. Ó. Perea; CORDE), proporciona una explicación de su origen: puesto que la fruta constituía el postre más corriente, al agregársele ciertas pastas fritas, estas pasaron a denominarse frutas de sartén (cfr. DCECH, s. v. fruta).
} 
vnas quatro vezes e frito fecho commo buñuelos e comido con miel en ayunas (a1429 Chirino, 132).

(33) y dos calderas de aceite mayores que las de un tinte servían de freír cosas de masa, que con dos valientes palas las sacaban fritas y las zabullían en otra caldera de preparada miel que allí junto estaba (1615 Quijote, II, cap. 20, p. 793).

Tostar se documenta desde el siglo XIII con su significado general de 'someter [una cosa] al fuego para que se deseque y tome color' (CORDE) y se aplica pronto a los alimentos. Estos se tuestan generalmente sobre la parrilla o las brasas, de donde la estrecha relación con lo asado, conexión que Covarrubias pone de relieve en dos entradas de su Tesoro: "Tostar. Assar sobre las ascuas, [...]" (s. v. tostar), y "Asar. Tostar las carnes al fuego, [...]" (s. v. asar; cfr. s. v. assar). Como todavía señala Autoridades, resalta en tostar el hecho de que el proceso de transformación es relativamente breve y controlado. El tostado se aplica a algunos alimentos prototípicos como las legumbres - ya Chirino (p. 96) habla de "lantejas tostadas"- y los frutos secos:

(34) ["Dela dieta y del regimiento del estomago frio e humido":] E estorue todas las fructas, saluo algunas vezes auellanas tostadas (1495 Gordonio, 2.1030).

(35) Reçeuta para hazer turrones. [...] Y como [sc. la miel] esté cozida, echad dentro piñones, o almendras, o abellanas tostadas y mondadas (a1525 MMugeres, 84).

También se tuesta el pan, sobre todo las rebanadas o sopas que sirven de base a muchos preparados gastronómicos de la época, así como las tortillas:

(36) E desque despierte denle bino bueno aguado con otro tanto [sic] agua a beuer, [...], o sopa de pan tostada en ello si la pudiere mascar (a1429 Chirino, 92).

(37) y despues tomar reuanadas de pan quitada la corteza: \& tostarlas: \& raerles lo quemado: y escaldar estas sopas conel dicho caldo: (1529 Nola, f. 50r).

(38) y en teniendo hechos los artaletes ponlos en vna caçuela vntada con manteca, y pon la sobre brasas: y quando los artaletes estuuieren tostados por la parte de abaxo, bueluelos, porque se tuesten de la otra parte (1611 Montiño, f. 66v).

(39) y reboçaras estas tortillas de borrajas con yemas de hueuos, y frielas que esten bien tostadillas: [...] (íd., f. 165r). 


\subsection{Verbos culinarios específicos}

Los verbos que se tratan en este apartado se refieren a procedimientos de elaboración más técnicos, son menos recurrentes en los textos, y algunos de ellos aparecen relativamente tarde, usándose sobre todo en los tratados gastronómicos.

Ahogar parece significar, como el moderno rehogar, 'freír trozos de carne o de un vegetal con cebolla cortada y/o tocino en aceite de modo que los trozos no se doren sino que queden sumergidos en su jugo'. Este empleo culinario del verbo aparece y abunda en las obras de Granado (1599) y Martínez Montiño (1611). Además, Covarrubias (1611: s. v. ahogar) menciona la lexía compleja carnero ahogado "cierta manera de guisado". El mejor indicio de la buena implantación del concepto en la lengua de principios del siglo XVII es el hecho de que también forma parte de los nombres de otros platos, como palominos ahogados (1611 Montiño, f. 49r-v). En Estilo de servir a príncipes de Yelgo de Vázquez (1614) figura entre las destrezas profesionales de los cocineros de casa importante "saber ahogar un lomillo de vaca en el horno" y "ahogar un capón, o gallina, que se ahogan de muchas maneras" (Pérez Samper, 2000-2001: 336337).

Avahar 'calentar con vaho', documentado desde 1500 más o menos (CORDE), aparece como término culinario en Nola:

(40) hazer las sopas muy delgadas. y estouarlas o abaharlas conel caldo (1529 Nola, f. 65v),

y a continuación se encuentra en varios textos de la época clásica, casi siempre aplicado a las rebanadas de pan, de modo que sopas avahadas se difunde como denominación lexicalizada de una preparación presente en muchos platos ${ }^{5}$. Covarrubias define el verbo de modo similar:

(41) llaman abaharla [sc. alguna cosa] quando desviada del fuego la ponen ropa, para que aquel baho y calor que sale della la buelva a recozer; y de aquí dezimos sopas abahadas (1611 Covarrubias, s. v. baho),

mientras que Autoridades (s. v. avahar) propone una descripción ligeramente diferente al precisar que "con el vaho se recalientan las sopas, u otro guisado, puesto encima de la olla de agua que está hirviendo". De esta definición diverge a su vez el significado que se manifiesta en varias recetas de Granado:

\footnotetext{
${ }^{5}$ P. ej.: "Por que hazia en casa mas costa de sopas abahadas, que haze el asno de grançones de paja aceuadada" (a1566 Alonso de la Vega, Tragedia llamada Seraphina, ed. M. Menéndez y Pelayo; CORDE); "Si acaso estaba en casa, le daban el hervor de la olla, sopitas avahadas, carne sin hueso" (1604 Mateo Alemán, Segunda parte de la vida de Guzmán de Alfarache, ed. J. M. Micó; $C O R D E)$.
} 
(42) [sc. los limones] cuezan con mucho fuego, hasta que esten muy tiernos por estremo, y en estandolo, apartarlos de la lumbre, y abaharlos en otra agua tibia (1599 Granado, f. 395v).

Parece que en este caso el alimento, después de someterse a cocción, se retira del fuego y se deja enfriar despidiendo vapor $^{6}$.

Escaldar 'calentar' está atestiguado desde Berceo (CORDE), y su acepción culinaria es 'calentar o cocer ligeramente [un alimento] cubriéndolo de caldo o agua hirviendo', técnica que se aplica sobre todo al pescado y a las sopas:

(43) La lamprea quiere ser biua: y escaldarla con agua caliente (1529 Nola, f. $55 \mathrm{v})$.

(44) y despues tomar reuanadas de pan quitada la corteza: \& tostarlas: [...] y escaldar estas sopas conel dicho caldo (íd., f. 50r).

Además de Nola, lo emplean también Granado y Martínez Montiño.

Escalfar se consigna por primera vez en La fazienda de Ultra Mar de Almerich (c1200, CORDE) y al comienzo significa simplemente 'calentar'. Su acepción culinaria 'cocer [un huevo] en agua u otro líquido hirviendo' se documenta ya hacia 1400:

(45) El .iij. catamiento [sc. de los huevos], segun el cozimiento, ca los que son escalfados en agua y blandos son liuianos de moler y de buen humor (1381-1418 Sevillana medicina, 234),

y más tarde en el Tratado de patología, en Lobera de Ávila, así como en los tratados de cocina de Hernández de Maceras y Martínez Montiño. La difusión de escalfar en español se debe tal vez a la influencia de las variedades orientales de la Península dado que desde antiguo el verbo estaba bien implantado en aragonés y en catalán (DECLlC, s. v. cald).

Estofar 'cocer [un guisado] a fuego lento' se introduce relativamente tarde entre los verbos culinarios del español, pero el procedimiento al que se refiere llegará a ser uno de los más usuales. La forma etimológica y más antigua del verbo es estufar ya que se trata de un derivado de estufa 'aposento cerrado y caldeado artificialmente'7. Por ello, estufar se usaba antiguamente en el sentido de 'tratar [a una persona o un miembro del cuerpo] con vapores o humos de hierbas medicinales', atestiguado en los tratados médicos desde mediados del siglo $\mathrm{XV}(C O R D E)^{8}$. Como verbo culinario se encuentra por primera vez en Nola:

\footnotetext{
${ }^{6}$ En otras recetas de Granado, el procedimiento se aplica a los limones (f. 393r, 417r-v), al azahar (f. 394r), las berenjenas (f. 397v), las nueces (f. 414r) y a las zanahorias (f. 422r).

${ }^{7}$ En los primeros siglos de la historia del castellano, la forma estofar se reservaba para otro verbo, derivado de estofa 'material de cualquier clase' ( $<$ fr. ant. estofe, cfr. fr. mod. étoffe), que significaba 'decorar, adornar'.

${ }^{8}$ En la traducción castellana del Libro de Propietatibus Rerum de Bartholomaeus Anglicus realizada por fray Vicente de Burgos (1494) se encuentra la variante estubar: "Las hojas del
} 
(46) \& quando el manjar blanco tornare como queso assadero entonces es señal que esta cozido: \& puedes poner entonces la agua rosada: \& despues la gordura de la olla, empero que sea limpio que no aya enel tocino: \& sepas que de vna gallina sacaras seys escudillas: \& sacalo fuera del fuego a sudar de manera que se estube bien: (1529 Nola, f. 16v).

(47) toma vna caçuela [...] \& echalos [sc. los higos] dentro meneandolos vn poco: y despues pon esta caçuela sobre las brasas: \& bien atapada de manera que se estufen alli. \& quando esten estofadas: \& se aura embeuido enellas toda la humidad del vino menearlas vn poco: (íd., f. 37r).

En la cita (46) estube corresponde a la forma estubar del original catalán, y estufen en (47) refleja stufen del texto catalán. Teniendo en cuenta que el autor de la obra original estaba familiarizado con las tradiciones culinarias italianas, puede suponerse que por lo menos el verbo catalán estufar se basa en el it. stufare "metodo di cottura in umido, a calore mite e protratto e con recipiente coperto" (Carnevale, 2011: s. v.). Probablemente por la influencia de las numerosas ediciones castellanas de la obra de Nola, estufar se introdujo en el léxico de los cocineros de la Corona de Castilla-León, pues lo encontramos más tarde en los tratados de Hernández de Maceras y Martínez Montiño. He aquí unos fragmentos que ilustran su significado:

(48) Para hazer carnero estofado, se ha de tomar el carnero del lomo, ò pierna, y hazerlo pedaços, [...], y se han de echar en vna olla, con vn poco de tocino gordo muy bien picado, echandole de todas especias, clauo, açafran, y pimienta, y gengiure, y canela, y vnos ajos menuditos en pedaços, y vna cebolla picada, [...] se ha de menear muy bien, y se ha de poner a la lumbre, y sera mejor en rescaldo que no en lumbre, tapandolo con vn plato gordo, ò tapadera que venga justa a la olla, para que salga menos baho; (1607 Maceras, f. 21-22).

(49) y despues lo [sc. el pernil] podras acabar de cozer, y estofarlo has con harto vino, y vn quartillo de vinagre, y las yeruas del jardin, saluia, y mejorana, y hisopillo en vn caço, y echarle del cozimiento en que se cozio hasta que se bañe, y taparlo has con vna cobertera, y cueça media hora: (1611 Montiño, f. 220v-221r).

También Covarrubias da una detallada definición de este concepto:

(50) Estofado. Vale algunas vezes el guisado que se haze, que ni es asado ni cocido, como la pierna de carnero estofada. Métenla en una olla vacía, bien mechada y llena de clavos y astillicas de canela, y a fuego lento se va ella coziendo entre sí, con sólo el calor y el tufo, que es un ayre denso (1611 Covarrubias, s. v. estofado).

sahuco \& las cortezas o el fruto cochas en agua salada disuelven la hinchazon de los pies si con ello fueren estubados" (eds. $\mathrm{M}^{\mathrm{a}} \mathrm{T}$. Herrera / $\mathrm{M}^{\mathrm{a}} \mathrm{N}$. Sánchez; CORDE). 
Con respecto a la forma, Maceras vacila entre estufar y estofar, mientras que Montiño prefiere claramente estofar, al igual que Covarrubias y más tarde $A u$ toridades (aunque estos diccionarios mencionan todavía estufar y estufado como variantes). Además, en las obras de Maceras y Montiño el participio estofado se da con alguna frecuencia como parte integrante de denominaciones de platos, $\mathrm{p}$. ej. en carnero estofado, barbos estofados, ánades estofadas, truchas estofadas, etc. En cambio, sorprende por su ambigüedad la actitud de Granado. Puesto que la mayoría de sus recetas que contienen este verbo se basan en Scappi, muchas ofrecen la forma estufar, condicionada por el it. stufare. Sin embargo, en varios casos Granado parece considerar estufar poco corriente en español y lo sustituye o explica por sinónimos como ahogar, sudar o por el catalanismo estovar 'ablandar':

(51) Para assar el lomillo de la vaca en assador, y para ahogarlo, y estouarlo. (1599 Granado, f. 50v); [corresponde a:] Per arrostire nello spedo, e stufare il lombo di boue, o di uaccina (1570 Scappi, lib. 2, cap. 8).

(52) Para poner a estufar, o sudar a pedaços el Sollo con vino blanco, vinagre, agraz, y agua. (1599 Granado, f. 158v); [corresponde a:] Per stufar pezzi di Storione con uin bianco, agresto, aceto, \& acqua (1570 Scappi, lib. 3, cap. 2).

Perdigar significa originariamente 'asar superficialmente [la perdiz]', valor que se encuentra todavía en el primer testimonio de la palabra, en el Vocabulario español-latino de Nebrija. La voz, atestiguada en varios textos del Siglo de Oro, es empleada con frecuencia por Granado, Maceras y Montiño, y también la registra Covarrubias (s. v. perdigón): "Perdigar, poner sobre las brasas la perdiz antes de asarla, y dízese de qualquier otra ave, y esto se haze con mucha presteza". El verbo se aplica también a otras aves, a otras clases de carne y a otros materiales culinarios:

(53) para estos podras hazer los vasos de pasta de maçapan, perdigandolos primero (1611 Montiño, f. 142v).

(54) Las alcachofas [...]: Limpiarlas de las hojas mas viejas y de la cascara del peçon, y cortales las puntas hasta cerca del medio: luego perdigalas en agua, (íd., f. 145r-v).

Sancochar 'cocer ligeramente', atestiguado aproximadamente desde 1400 (Biblia Escorial, CORDE), pero sin duda patrimonial, es aún poco frecuente en nuestros tratados médicos y culinarios. Villena (p. 96) explica que el "cuero del escudo" del jabalí se conserva "pelado e fecho tuérdigas e sancochado"; y el médico Fores (p. 91) afirma que las alcaparras son buenas "vn poco socochadas en el principio del comer", mientras que Herrera (f. 125v) comenta que las berenjenas pueden consumirse "sancochadas en agua y espremidas cozidas con miel o arrope". Por fin, Maceras (pp. 103-104) señala que las ranas deben de- 
jarse en agua hirviendo hasta que "se salcochen". De las variantes formales socochar y salcochar, la primera parece abonar la hipótesis de Corominas y Pascual (DCECH: s. v. cocer) de que la sílaba inicial del verbo representa el preverbio SUB-, en tanto que la segunda indica que algunos usuarios lo relacionaron con $s a l^{9}$. Lo más probable es, pues, que sancochar represente un derivado del participio fuerte sancocho (< SUBCOCTUM) aunque, curiosamente, este último no está documentado hasta el siglo XIX (vid. § 4.1.).

Sofreír 'freír ligeramente' se halla de manera recurrente en la obra de Nola como equivalente del cat. sofregir (p. ej: "\& despues tomar cebolla cortada bien menuda: \& soffreyrla con buen tocino”, f. 26v) y también figura en los tratados de Vallés y Granado, influenciados por Nola. En cambio, el verbo falta en las obras de Maceras y Montiño así como en Covarrubias. Autoridades (s. v.) lo registra, pero sin aducir ejemplos. Por lo visto, se trata de un catalanismo de difusión tardía en español.

\subsection{Algunos procedimientos de transformación sin uso del fuego}

Los lexemas que se han examinado hasta aquí se refieren a los procedimientos culinarios propiamente dichos, que incluyen como elemento semántico esencial el empleo del calor. Sin embargo, la elaboración de un plato suele implicar otras muchas manipulaciones (p. ej. batir, cortar, derretir, desalar, escurrir, exprimir, majar, rallar, etc.) que no se analizan aquí.

En cambio, no se deben olvidar las demás técnicas de elaboración de los alimentos, especialmente las que permiten su conservación. Los textos, incluidos los tratados de cocina, suelen ser menos explícitos a este respecto, aunque están muy presentes en la mayoría de las obras los productos de tales métodos, como el queso y el requesón, la carne y el pescado curados, secos, en adobo o en escabeche, el vino y la sidra en cuanto zumos fermentados, etc. Desde el punto de vista de la lexicología histórica, entre los más interesantes están el adobado, la salazón y el secado de la carne y el pescado.

Adobar.-A partir del siglo XIV el valor culinario inicialmente muy general de este verbo, de 'preparar [la comida]', ya tratado más arriba (§ 3.1.), empieza a desvanecerse ante la difusión del significado más restringido de 'sazonar [un alimento] con sal, hierbas aromáticas y/o especias, etc.' (vid. DEM, s. v. adobado y adobar, y las citas 14-16):

(55) Busco muchas vïandas costosas e preçiadas, / de diuersos sabores rricamente adobadas, / que a yantar e a çena sienpre finquen sobradas: (c 1378-1406 Pero López de Ayala, Rimado de Palacio, ed. G. Orduna; CORDE).

\footnotetext{
${ }^{9}$ Se trata sin duda de una etimología popular, mencionada también en Autoridades $s . v$.
} 
(56) del cabrito el assado quando es muy gruesso \& lo otro adobado con açafran \& canela \& gengibre poco. Del carnero lo mejor es cozido. o adobado (a1400 Estéfano de Sevilla, Visita y consejos de médicos, ed. P. SánchezPrieto Borja; CORDE).

(57) Adobar [...] algunas vezes sinifica sazonar el manjar, como carnero adobado, que se usava dar por mucha fiesta antiguamente en las cofradías y en las bodas (1611 Covarrubias, s. v.).

La especialización semántica de adobar revela otra línea maestra de la cultura culinaria europea en general y de la castellana en particular, la aplicación de determinadas combinaciones de sabores a los alimentos. Y, de modo similar a la evolución de guisar, el mismo cambio se produce tanto en el verbo adobar como en sus nominalizaciones adobado y adobo, que designan tanto el proceso como, sobre todo, su resultado o producto.

Ahora bien, este significado abarca toda una serie de variantes y situaciones diferentes. En primer lugar, adobar y sus nominalizaciones se usaban en el sentido más preciso de 'sazonar vegetales o frutos, crudos o cocidos, con sal, vino o vinagre, etc., especias y hierbas aromáticas, para darles sabor o para conservarlos', lo que recuerda en cierto modo a otra categoría clave del sistema culinario de Lévi-Strauss, la de la fermentación (o putrefacción):

(58) y las azeytunas verdes talladas y remojadas nueue dias en agua y en sal, y despues adobadas con finojo, dan apetito de comer y esfuerçan el estomago, [...] (1384-1418 Sevillana medicina, 178; cfr. 197: alcaparras "adobadas con azeyte y con vinagre y culantro").

(59) ["Dela flaqueza del apetito":] e aprouechan esso mismo azeytunas adobadas e persicos en conserua, esparragos adobados e peçes salados (1495 Gordonio, 2.1004).

(60) [contra el vómito:] E sus comeres: mjlgrana e sumaquia e graçia e lo quel semeja, adobados con culantro seco (a1500 TrPatología, 414-415).

En algún caso, especialmente en contextos dietéticos, se adoba también con sustancias dulces, como el azúcar, el aceite de almendras dulces o ciertos arropes:

(61) den le aquellas cosas que son de dura digestion, assi commo son [...] calabaças adobadas con azeyte de almendras dulces e con açucar, las estremedidades delas animalias e las tripas que se adoben con vino e açucar (1495 Gordonio, 2.1038).

Otra variante semántica de adobar es la de 'confeccionar un guisado de carne o pescado que incluye ingredientes como sal, agua o vino, verduras así como hierbas aromáticas, especias y otras sustancias saporíferas'. Estamos, pues, ante la confección de platos complejos y elaborados, como ya se ha podi- 
do ver a propósito del significado general de adobar (\$ 3.1.). Lo esencial es en este caso que las piezas de carne o pescado maceren durante cierto tiempo en el adobo, por lo que son frecuentes las colocaciones "en adobo", "echar en adobo" y "estar en adobo". No obstante, la mayoría de los testimonios impiden determinar si el adobo en que maceran las piezas las acompaña también durante la cocción o no:

(62) Carnero menudo es adobado con cebollas y con ajos, y con canela y con açafran y miel tostada; y esto es conuenible para en tiempo frio y para las complisiones frias, y es dañoso a los hombres colericos (1381-1418 Sevillana medicina, 215).

(63) Cetaria. son estanques do estan grandes pexes o otros menores o es logar do se faze para ellos adobo o salsa en que se lançan: y este liquor se llama adobo o salmuera (1490 Palencia, f. 73r).

(64) Adobos de solomillos. [...] luego haras vn adobo con agua, y sal, y vinagre, y hisopillo picado muy menudo, y mejorana tambien picada menuda, y vn poco de vino blanco: y si quisieres echar vn poco de ajo, bien podras: saçonarlo has con todas especias (1611 Montiño, f. 104r).

En otros ejemplos sí se precisa que la carne o el pescado se retira del adobo antes de la cocción:

(65) Para hazer estas empanadas de ternera, se ha de echar la ternera en adobo, con sus ajos, sal, y oregano todo muy bien majado; y ha de estar vn dia, o dos en el adobo, y quitada del adobo, se ha de perdigar de suerte que estè medio assada, y se mezclara con tocino gordo, echandole especias, y agraz, [...] (1607 Maceras, 33).

En la cita (63) se señala la sinonimia de adobo y salmuera, también evocada en otros textos. Parece que la salmuera, compuesta de agua y sal, constituía simplemente el adobo más elemental. En este contexto hay que mencionar también escabeche, en ocasiones equivalente contextual de adobo, según se puede desprender de muchas recetas de Nola aunque, por otra parte, escabeche se emplea igualmente en el sentido de 'carne en adobo' (p. ej.: “Escabeche es fecho de carne y de vinagre y de açafran, y es frio y seco", Sevillana medicina, 216).

Adobar y adobo simbolizaban, pues, unos procedimientos culinarios refinados, motivo por el cual eran criticados por ciertos moralistas partidarios de una alimentación frugal:

(66) Yo vi tiempo que en el mundo non avía uso de tales cosas, e non sabían qué cosa era adobo de vinos nin cozinar tantos comeres, [...] (1430-1440 La Torre, 308).

(67) no mirando lo que Plinio dize contra ello [...]: "El manjar simple para los hombres es muy provechoso, y el ayuntamiento de manjares es pestilen- 
cia y más dañoso que pestilencia quando los manjares son adobados" (1553 Torquemada, 331-332; cfr. 339).

Salar 'poner en sal [un alimento] para conservarlo' existe desde el siglo XIII (CORDE). Más tarde, en el Libro de buen amor, se mencionan la "salada sardina" (v. 1103a) y la "carne salada" (v. 1030e), además de que también se habla de "echar en sal" (un puerco y un lechón, v. 1115d). Por otra parte, Villena comenta en varias ocasiones los diferentes estados o resultados que se dan al elaborarse la carne, entre los cuales menciona la salazón:

(68) Lo ál [sc. de la cabeza del puerco] parten en dos partes al luengo [...] e saladas o frescas danlas cochas, (1423 Villena, 97).

$\mathrm{Y}$ en los tratados médicos, la carne salada suele ser objeto de numerosas diferenciaciones y consejos de orden dietético. En este contexto se impone una referencia a salpreso 'salado': lo emplea ya Berceo ("pescados salpresos", CORDE), y la palabra figura también en el Libro de buen amor ("anguillas, I salpresas e trechadas", vv. 1105a, b; "carne salpresa", v. 1274a). Parece estar compuesto de sal y preso, antiguo participio fuerte de prender, de modo que salpreso vendría a significar literalmente 'tomado de sal' ${ }^{10}$. A partir de la segunda mitad del siglo XVI se usa igualmente el verbo salpresar, registrado junto a salpreso por Covarrubias y en Autoridades. Salpreso era sin duda una voz popular, lo que podría explicar su presencia en el Libro de buen amor y, por otra parte, su ausencia - al igual que la de salpresar- de los tratados culinarios de Nola, Hernández de Maceras y Martínez Montiño. Granado, en cambio, emplea el verbo en varias ocasiones; he aquí uno de sus fragmentos más elocuentes al respecto:

(69) Como se ha de salpresar, o cozer cualquier parte de la vaca. Cortaras las costillas, los pechos, o qualquier otra parte de la vaca en muchos pedaços, pondrasles sal, y en vn vaso de tierra, o de madera compondras los vnos sobre otros, y cubrirlos has con vna tabla, y cargarlahas de buen peso mientras haze la salmuera, es a saber en el verano quatro dias, y en el inuierno ocho (1599 Granado, f. 49r).

$\mathrm{Al}$ secado de la carne y el pescado hay pocas referencias en los textos, pero se encuentran varias alusiones a sus productos, la carne cecina (desde 1250, CORDE) o cecina (a partir de 1305, CORDE), adjetivo posteriormente sustantivado, del que

\footnotetext{
${ }^{10}$ Corominas y Pascual (DCECH: 5.133) suponen que -preso se remonta al lat. SPARSUS 'esparcido', hipótesis poco plausible por motivos fonéticos — se esperaría por lo menos un predominio de la grafía con -ss- (-presso), en realidad muy minoritaria-. Corominas retoma esta propuesta en su diccionario etimológico del catalán, a propósito de salprès (DECLlC: 7.611-7.612), pero admite también la posibilidad de que se trate de un compuesto de sal y pres (< PREHENSUM).
} 
deriva el verbo ceci(n)ar ("Galludos, en quanto son ceciados en el Sol sin sal, fazense templados”, 1381-1418 Sevillana medicina, 250).

Otra actividad culinaria importante era la elaboración de conservas, esto es, la conservación, en azúcar o miel, de frutas, frutos secos y, a veces, hortalizas, hierbas o especias. Cuando se trataba de piezas pequeñas, especialmente de frutos secos, estas se llamaban confites, voz atestiguada desde el Libro de buen amor ("Sabed que de todo açucar allí anda: bolado, / polvo, terrón e candi, e mucho del rrosado; / açucar de confites e açucar violado", vv. 1337a-c). Como se ve en este y en otros textos de la época, la confitería tuvo un desarrollo notable ya en la Edad Media, y más tarde se le dedicaron varios tratados. Por otro lado, se puede recordar que durante buena parte del período estudiado la divisoria entre lo dulce y lo salado fue menos nítida que hoy en día puesto que en la gastronomía refinada el azúcar — considerado una especia - era un ingrediente usual en muchos guisados de carne y verdura.

\section{DenOMinaciones DE Clases DE Platos}

Las palabras que se tratan en este apartado se caracterizan por basarse en conceptos muy generales del mundo culinario: el primer ámbito es otra vez el de los actos culinarios que se acaban de comentar, el segundo abarca las principales vasijas usadas para realizar las preparaciones. Evidentemente, estos dos modos de denominar grandes conjuntos de manjares no son los únicos. Hay otros, como los potajes, las empanadas y pasteles o las tortas, sumamente numerosos en los libros de cocina antiguos. Aunque la tipología general de los platos y confecciones así como sus denominaciones quedan en gran parte por estudiar, las dos clases que se analizan en este apartado parecen ser fundamentales.

\subsection{Participios sustantivados de verbos culinarios}

La importancia primordial de los procedimientos de elaboración, no solo para la antropología cultural sino también para la lexicología de los nombres de platos, viene subrayada por el hecho de que toda una serie de denominaciones consta simplemente de los participios sustantivados de ciertos verbos culinarios. La relación entre proceso y resultado ha sido destacada en la lingüística cognitiva, especialmente en la teoría de los frames (Blank, 1997: 251), y se ha tratado también en relación con el vocabulario culinario (p. ej. Plaza, 2012: 207-208).

La lexicalización de estos participios se produce en varias etapas. La primera consiste en que el participio sin determinante se emplea con función de complemento directo en colocaciones como "comer guisado" (desde el siglo XV, 
CORDE) o "comer cocho/cocido" (citas 26 y 27), interpretables en el sentido de 'comer algo que se ha guisado o cocido'. La segunda etapa se manifiesta en sintagmas con artículo neutro como lo asado o lo cocido 'conjunto de alimentos asados o cocidos', presentes en algunas de nuestras citas (18-20, 22). Ocasionalmente se encuentran con el mismo valor también el asado y el cocho/cocido:

(70) generalmente, deuemos adelantar el cocho ante que el assado, el laxatiuo ante que el estiptico (1381-1418 Sevillana medicina, 294).

Por fin, la lexicalización completa se da en sustantivos como (el) asado y su plural (los) asados referentes a manjares concretos. Sin embargo, tales lexicalizaciones se producen en varias épocas, según cada lexema. Las más tempranas se manifiestan en guisado, ampliamente documentado desde el siglo XV ( $\$$ 3.1.; cfr. las citas 6 a 8). A partir de la misma centuria se encuentra también adobado:

(71) Martifrium. es vn linaie de adobado o maniar fecho de pexes (1490 Palencia, f. 267r; cfr. f. 430v).

(72) Pues, ¿adobado no hacía?, sobre que cuantos traperos había en la cal de la Heria querían proballo, y máxime cuando eran un buen pecho de carnero (1528 Lozana, 97-98).

(73) Adobado de carnero (1529 Nola, f. 50v).

En cambio, (el) asado es raro en el período estudiado, y los primeros testimonios no se encuentran antes del siglo XVI (aunque estas circunstancias podrían explicarse por el escaso interés de los tratadistas culinarios por esta técnica):

(74) porque no me tenía más de una olla y un asado para comer (1589 Juan de Pineda, Diálogos familiares de la agricultura cristiana, ed. J. Meseguer Fernández; CORDE).

Tampoco abundan todavía las lexías complejas como (el) asado de cordero. (El) estofado está atestiguado desde el siglo XVII ("un gigotillo, un poco estofado de ternera, una cazuela de buenas aves" (1641 Andrés Sanz del Castillo, La mojiganga del gusto, ed. E. Cotarelo y Mori; CORDE), mientras que (el) cocido parece ser una creación del siglo XIX (CORDE). De cocinado solo existe el compuesto (el) malcocinado 'guisado de tripas que se vende en puestos callejeros' (siglos XIII-XIX, CORDE). Por fin, hay que volver sobre la enigmática historia de sancocho, participio fuerte basado en el lat. SUBCOCTUM y del cual se derivaría el verbo sancochar (vid. § 3.3.). La dificultad consiste en que no se han encontrado testimonios antiguos de sancocho, cuya trayectoria documentada se inicia en el siglo XIX, época a partir de la cual se usa como sustantivo, deno- 
minando diversos guisados hoy en día bien arraigados en las tradiciones culinarias populares del mundo hispánico.

\subsection{Empleo metonímico de términos referentes a vasijas}

Otro modo característico de denominar ciertas categorías fundamentales de preparaciones culinarias consiste en el uso metonímico de los nombres de recipientes usados para realizarlas.

En cazuela la transferencia metonímica resulta particularmente fácil de mostrar. Al principio, los autores exponen simplemente cómo los ingredientes de un plato se cuecen en una vasija de este nombre. Más tarde, la frecuencia del procedimiento se manifiesta en la locución adverbial sin artículo "en cazuela":

(75) y assenla [sc. la lamprea]; o adobada en caçuela (1381-1418 Sevillana medicina, 246).

(76) Ca si fueren adobadas [sc. las gallinas] o en mitraust o en caçuela [...], non son menester aquellos tajos (1423 Villena, 90).

(77) $\mathrm{Si}$ fuere de friura, toma tres yemas de hueuos e su peso de mjel espumada e cojalo todo en caçuella; (a1500 TrPatología, 454).

A continuación, aparece cazuela junto a denominaciones de otras clases de preparados, con lo cual resulta claro que la palabra indica ya una categoría de guisados de todos conocida:

(78) [A propósito del dolor de las articulaciones:] vse lo asado e lo frito e las caçuelas e las çeçinas (a1500 TrPatología, 809).

(79) Guardanse las verengenas heruentadas en aguasal y esprimidas y echadas en vinagre fuerte para despues hazer dellas caçuelas y otros guisados: y asimismo sancochadas en agua (1513 Herrera, f. 125v).

Y, por fin, aparecen lexías complejas con dos configuraciones sintácticas concretas y muy frecuentes en los tratados de cocina. La primera contiene el nombre del ingrediente principal seguido del complemento en cazuela:

(80) Berengenas en caçuela (1529 Nola, f. 25v).

(81) Arroz en caçuela al horno (íd., f. 27v).

En la segunda, el sustantivo es cazuela, mientras que su complemento proporciona la información sobre el plato concreto:

(82) Pues, ¿boronía no sabía hacer, por maravilla? Y cazuela de berenjenas moxíes en perfición, cazuela con su ajico y cominico y saborcico de vinagre 
[...] Y cazuelas de pescado cecial con oruga y cazuelas moriscas, por maravilla, y de otros pescados que sería luengo de contar (1528 Lozana, 98; cfr. 231).

(83) Panarizo: - Mira: en la tierra de Xauxa, hay muchas caçuelas con arros y huevos y queso (1567 Rueda, 164).

(84) Como se ha de hazer vna caçuela de conejos a la portuguesa (1607 Maceras, 42).

Marcella Ciceri (1992) y Teresa de Castro (2002: 209) señalan que las cazuelas eran platos característicos de la cocina morisca, hecho ilustrado por nuestra cita (82).

Cocina significaba desde antiguo también 'olla' y luego por metonimia 'caldo':

(85) [Penitencia que el fraile impone a Don Carnal:] el viernes pan e agua comerás, e non cozina; (1330-1343 Libro de buen amor, v. 1168b).

(86) Cozina caldo. ius. iuris (1495 (?) Nebrija, Vocabulario, s. v.).

(87) Algunos escuderos que biven en aldeas, no sabiendo hazer esta diferencia entre potage y caldo, por no conformarse con los aldeanos en dezir cozina, sin guardar la diferencia dizen siempre potage (1535 Juan de Valdés, Diálogo de la lengua, cit. por Gemmingen, 1987: 492-493, nota 4).

(88) En algunas partes llaman cozina el caldo (1611 Covarrubias, 329a, s. v. cozina).

Estos testimonios muestran que cocina 'caldo' representaba una expresión popular que con el tiempo quedó relegada a ciertas hablas rurales, según confirma también Autoridades, lo que explica su ausencia de los tratados de culinaria.

Olla es, junto a cazuela, el ejemplo más llamativo del cambio metonímico de continente a contenido. Al principio, tal contenido parece poco preciso, como demuestra la siguiente explicación, en la que es cuestión de un brebaje para uso veterinario:

(89) fazle [sc. al caballo] una olla destas cosas [que] seran aqui escriptas: tomar manteca cocha de vacas o de ovejas .v. libras \& sevo de rinnonnada de cabron \& de carnero .v. libras, azeit una libra, sain de puerco viejo .v. libras, miel quatro libras, ajos quatro cabeças, vino un azumbre, [...] (c1275 Libro de los caballos, ed. M. ${ }^{\mathrm{a}}$ Teresa Herrera / M. ${ }^{\mathrm{a}}$ Nieves Sánchez; CORDE).

Pero pronto se manifiesta el significado de 'guisado de carne (y de verdura)' que será el de olla durante toda la época estudiada: 
(90) [sc. en Vizcaya] fazen caldero y olla del vientre de la vaca o del carnero y cuezenlo en el, assi como en la olla [...] (1381-1418 Sevillana medicina, 213).

En varios textos del siglo XVI se precisa el sentido de la palabra y el contenido concreto de la olla:

(91) Pues, ¿ollas en tiempo de ayuno? Estas y las otras ponía yo tanta hemencia en ellas, que sobrepujaba a Platina De voluptatibus y Apicio romano De re coquinaria. Y decía esta madre de mi madre: "Hija, Aldonza, la olla sin cebolla es boda sin tamborín" (1528 Lozana, 98).

(92) Osorio.-Por mi pasatiempo, yo me quiero poner a contar de cuántas cosas está compuesta su merced de nuestra olla: carnero, vaca, tocino. / Don Lorenzo.-Esas son las tres potencias de la olla, como las de la [sic] alma memoria, entendimiento, voluntad. / Osorio.-Luego se sigue repollo, nabos, cebollas, ajos. / Don Lorenzo.-Esas son las cuatro virtudes cardinales. / Osorio.-Cabezas y pies de aves, culantro verde, alcarabea, cominos, todas especias; las demás yerbas yo no las conosco. Otro las cuente (1599 Dialogues, 86).

Recuérdese, además, la conocida semblanza de Don Quijote al comienzo de la obra, donde se caracteriza al personaje por su dieta, especialmente por su plato primero y principal, "una olla de algo más vaca que carnero" (I, cap. 1, pp. 35-36). También la palabra olla pasó a formar parte de lexías complejas que designaban platos específicos, como olla morisca (a1525 MMugeres, 58), olla de carnero (desde 1575, CORDE) y, sobre todo, olla podrida, cuyo referente es descrito y ponderado en muchos textos de la época clásica, como expone Monique Joly (1990) en su detallado estudio.

Puchero, que significaría inicialmente 'vasija en que se preparaban puches' y luego 'recipiente para cocinar' (atestiguado desde 1250, CORDE), es hoy en día denominación de varios guisados pertenecientes a distintas tradiciones gastronómicas regionales del mundo hispánico. Sin embargo, en el Siglo de Oro este valor culinario solo se documenta esporádicamente. Así, Covarrubias (s. v.) menciona la locución "Comer su puchero, contentarse con su passada", y Martínez Montiño (f. 213v) propone una receta de huevos en puchero.

\section{SÍNTESIS Y BALANCE}

El punto de partida de este estudio ha sido la idea ya ampliamente aceptada de la preeminencia de los guisados en la culinaria de las sociedades tradicionales de Europa, por lo cual los verbos relativos a los diferentes procesos de elaboración ocupan un lugar central en el léxico gastronómico, una posición a 
nuestro modo de ver más importante que, p. ej., los términos referentes a los distintos ingredientes. Ello motivó, sin duda, la progresiva especialización semántica de adobar y guisar (\$ 3.1.). Su significado general 'preparar, disponer' puede aplicarse también a la comida, en sintagmas como "adobar/guisar de comer". Sin embargo, la frecuencia con que se usaban estos verbos en contextos culinarios dio lugar a un proceso de especialización de ambos en dicho ámbito, de modo que adobar llegó a expresar la idea de 'sazonar [un alimento] con sal, hierbas aromáticas y/o especias, etc.', y guisar, la de 'preparar los alimentos haciéndolos cocer en un líquido o salsa, después de rehogados'. Esta especialización técnica condujo a una notable polisemia de los dos lexemas, fenómeno que Maryse Colson (2014: 62-63) ha descrito a propósito del fr. confire. El creciente número de acepciones de adobar y guisar podría estar en el origen de varios cambios en el campo de los verbos que expresan la noción general de 'preparar la comida'. Es posible que haya motivado, primero, la mayor frecuencia de uso de cocinar desde el siglo XV; segundo, la caída en desuso del significado genérico de adobar 'preparar [la comida]' a partir del siglo XIV; tercero, la limitación de guisar a 'preparar [una comida] sometiendo unos alimentos a cocción y a otras operaciones'; y, cuarto, la aparición de preparar como nuevo verbo genérico desde principios del siglo XVII, según demuestran los primeros testimonios del sintagma "preparar la comida" en el CORDE.

Pasando a los verbos que designan las principales operaciones culinarias con aplicación de calor - asar, cocer, freír y tostar- (§ 3.2.), deben recordarse las numerosas variaciones gastronómicas que permite la fórmula del guisado. Estas potencialidades confieren al verbo cocer un carácter prototípico dentro de este grupo y hacen que la cocción eclipse al primario procedimiento del asado en el discurso culinario. El protagonismo de cocer se manifiesta, entre otras cosas, en su polisemia ya que este verbo se refiere sobre todo a dos clases de actos, (1) la transformación de un alimento dentro de una vasija por medio de un líquido hirviendo y (2) la elaboración de un preparado de masa en el horno. El rasgo esencial de tales prácticas consiste, pues, en que los alimentos se preparan en un espacio cerrado y/o submergidos en un líquido. A este propósito hay que recordar nuevamente las empanadas y los pasteles, que cobrarán una extraordinaria importancia en la gastronomía bajomedieval y renacentista. Su fórmula común consiste en que en un envoltorio de masa se colocan carne o pescado (a veces fruta), salsas, hierbas aromáticas, especias, etc. y que el conjunto se cuece en el horno. Las empanadas y los pasteles pueden comerse calientes o fríos, y en el segundo caso se trata también de una técnica de conservación. Desde el punto de vista antropológico, se observa aquí una doble mediación cultural, pues los ingredientes se ponen en una primera materia envolvente, la masa, tras lo cual la preparación se transforma en un segundo espa- 
cio envolvente, el horno. Freír, por su parte, se sitúa a caballo entre asar y cocer, compartiendo con el primero la viveza del fuego y con el segundo, la elaboración del alimento por inmersión. En cuanto a tostar, indica como asar la exposición directa al fuego o a las brasas, pero el tostado es un procedimiento más suave que, además, no se limita a la carne sino que se extiende también a las legumbres, los frutos secos, el pan, etc. El carácter primario que los antropólogos han atribuido al asado - un calor violento aplicado a la carne cruda- se convierte aquí en un método más concorde con la cultura culinaria.

Más heterogéneo resulta el grupo de los verbos culinarios específicos ( $\$$ 3.3.). La evolución de la alta gastronomía perceptible en los tratados de cocina desde fines de la Edad Media se manifiesta, entre otras cosas, en las distintas formas de cocción lenta en un líquido o mediante vapor, a las que se refieren avahar, escaldar, escalfar, estofar y sancochar. En la misma dirección apuntan las maneras de freír carnes o vegetales superficialmente (sofreír) o de modo que queden sumergidos y se cuezan en su jugo (ahogar). Incluso el acto de asar llega a tener una variante atenuada, llamada perdigar, que recuerda a tostar. Algunos de estos verbos, sobre todo sancochar, podrían ser antiguos, pero la mayoría de ellos (o, por lo menos, sus acepciones culinarias) parecen haberse introducido en castellano hacia el final de la Edad Media. Sin embargo, resulta difícil hacer precisiones sobre tal proceso puesto que los libros de cocina castellanos, que suelen contener los primeros testimonios de dichos términos, son tardíos y en parte tributarios de la tradición gastronómica catalano-aragonesa. Estas circunstancias explican sobre todo la escasa difusión de sofreír en el período considerado; pero también el caso de estofar ilustra la impronta catalana en el léxico culinario español. Además, el grupo de los verbos culinarios específicos muestra también menos estabilidad en su paso a la lengua moderna: $a v$ ahar parece haberse perdido como término culinario, y de perdigar se encuentran pocos testimonios en el español actual. Sancochar y su variante zancochar (CREA, DEA s. v.) han quedado limitados a la confección de una serie de platos regionales. En cambio, siguen usándose en la lengua general escaldar, escalfar, estofar y sofreír. Es sabido que en el siglo XX la alimentación y las técnicas culinarias, y con ellas el léxico gastronómico, se han diversificado notablemente, por lo que estos grupos de verbos son hoy en día mucho más numerosos.

En cuanto a la elaboración de los alimentos sin aplicación de calor (§ 3.4.), existen también algunos conceptos fundamentales, sobre todo los designados por los verbos adobar y salar. De ambos se puede decir que pertenecen tanto a la culinaria propiamente dicha, subrayando la importancia de los condimentos, como a las prácticas de conservación, y que se han mantenido hasta hoy.

Pasando a las grandes clases de preparaciones culinarias, dos de los procedimientos lexicogenéticos más significativos para denominarlas son (1) la nomi- 
nalización de participios de verbos culinarios y (2) la transferencia metonímica de tipo 'continente > contenido' en una serie de sustantivos que designan vasijas. Ambos procedimientos muestran cierta productividad pero, como es normal en la creación de palabras, no se aplican de manera sistemática ni intervienen en la misma época. Entre los participios sustantivados y enteramente lexicalizados (§ 4.1.) habrá que retener guisado, asado, adobado, estofado, cocido y sancocho. Estos sustantivos se utilizan también para formar denominaciones de platos concretos, pues se les pueden adjuntar complementos que precisen el ingrediente principal, aspecto que aquí solo se ha tratado de pasada. En español moderno todos ellos existen todavía aunque, debido a la gran diversificación de los platos en la alimentación del siglo XX, han perdido el protagonismo que tenían en la época considerada. Sobre todo cocido y sancocho han quedado limitados a la gastronomía regional.

Respecto del empleo metonímico de nombres de vasijas, destacan olla y cazuela. Olla designa una clase de guisado fundamental en la cocina castellana tradicional, que conlleva algunos ingredientes característicos como el tocino y ofrece muchas variantes según la zona geográfica, la estación, la clase social de los comensales y la época histórica. Las distintas clases de ollas no reciben denominaciones precisas hasta la época clásica (olla morisca, olla de carnero, olla podrida, etc.). Cazuela, sin complemento, tiene un significado menos delimitado que olla, aunque se perfila como nombre de un conjunto de manjares (cita 78). Abundan expresiones como "adobar en cazuela" (citas 75 y 76), y más tarde se dan ya nombres de platos concretos como berenjenas en cazuela (cita 80) y cazuela de berenjenas (cita 82). También estos dos términos han dejado de designar clases de manjares fundamentales en los códigos culinarios del mundo hispánico: ambos se siguen usando hoy en día como denominadores comunes de una serie de platos de connotación popular (y regional), aunque con mayor frecuencia cazuela que olla.

Unas observaciones finales sobre dos palabras que designan en principio recipientes, aunque estos no se utilicen para preparar la comida sino para servirla: escudilla y plato. Así, en las recetas es frecuente encontrar, al final del proceso de elaboración, una precisión de que el producto debe servirse en escudillas o en platos (de donde el verbo escudillar y el moderno emplatar).

Escudilla denomina una 'vasija semiesférica que se emplea para servir en ella caldos y otros compuestos líquidos'. Está emparentado con el cat. escudella, en el que el cambio metonímico a 'manjar compuesto, con caldo u otro líquido' se produjo ya en época antigua. En el término castellano este nuevo valor también existió, aunque parece más tardío y menos arraigado. Villena habla de "vianda d'escudilla o salsamento" (p. 80), y Martínez Montiño propone recetas tituladas "vna escudilla de caldo" (f. 242r), "vna escudilla de almendrada" (f. 242v), "vna escudilla de borrajas" (f. 243v), vna escudilla de almidón” (f. 309v), etc., en las que no queda claro si escudilla denomina una 
clase de preparación concreta o, simplemente, el recipiente y la cantidad del alimento que se sirve en él. En cambio, Granado ofrece numerosas recetas denominadas, p. ej., escudilla blanca de requesón, escudilla de macarrones a la romana, escudilla de huevos con harina, etc., en los cuales escudilla equivale a menudo al it. minestra del tratado de Scappi, que le sirve de modelo. Pero se puede suponer que el recurrente uso de escudilla por Granado se debe también a influencia catalana. Generalmente, los preparados que llama escudillas contienen caldo, hortalizas, cereales, leche, requesón, huevos, pescado, etc. —raras veces carne-, por lo que se administran preferentemente a los enfermos. Es sintomático de la precaria implantación de este valor metonímico de escudilla que no figure en Autoridades.

Algo similar ocurrió con plato. La nueva costumbre de servir los preparados culinarios en platos hizo que hacia 1500 esta palabra, por extensión, pasara a designar también el contenido de tal recipiente. Por ello, fray Hernando de Talavera dice en su Instrucción para el régimen interior de su palacio: "No quite el plato o manjar de la mesa sin que luego este alli otro a la mano" (ed. J. Domínguez Bordona; CORDE); y por los mismos años, en el Libro del conde Partinuplés (ed. N. Baranda; CORDE) se habla ya de "un plato de perdizes asadas". Estos ejemplos ilustran, pues, los orígenes de uno de los principales valores de plato en español moderno, a saber, 'guiso, o comida dispuesta para ser consumida' (DEA), equivalente a it. piatto, fr. mets, ingl. dish y al. Gericht. En la cita de Hernando de Talavera se documenta, además, la sinonimia de plato y manjar en el español clásico. Dentro del uso moderno, plato ha suplantado a manjar, que ya solo subsiste en el registro literario.

Los mecanismos lexicogéneticos que se acaban de describir contribuyen, a nuestro modo de ver, a formar el núcleo de un léxico culinario castellano que, desde fines del siglo XV, entra en un proceso de diversificación y elaboración. Este proceso viene impulsado por un creciente desarrollo de la cultura cortesana caracterizada, entre otros muchos aspectos, por una gastronomía cada vez más refinada. El vocabulario estudiado es, en principio, básico y común a toda la sociedad, aunque algunos de los verbos culinarios específicos tratados en el apartado 3.3. (ahogar, avahar, estofar, etc.) podrían pertenecer a un lenguaje profesional en vías de formación y atestiguado sobre todo en los tratados culinarios de la época clásica.

\section{CORPUS}

Arcipreste de Hita (1988): Libro de buen amor, G. B. Gybbon-Monypenny (ed.), Madrid, Castalia.

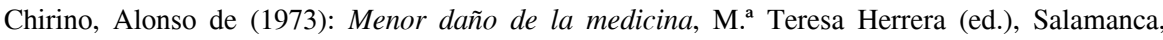
Universidad de Salamanca. 
Covarrubias, Sebastián (1987 [1611/1674]): Tesoro de la lengua castellana o española, ed. facsímil de Martín de Riquer, Barcelona, Alta Fulla.

Dialogues = Cid, Jesús Antonio (ed.) (2002): Pleasant and Delightfvll Dialogues in Spanish and English, profitable to the learner, and not unpleasant to any other reader, Madrid, Instituto Cervantes.

ETamorlán = González de Clavijo, Ruy (1999): Embajada a Tamorlán, Francisco López Estrada (ed.), Madrid, Castalia.

Fores, Licenciado (1993): Tratado vtil e muy prouechoso contra toda pestilencia e ayre corrupto, en M. ${ }^{a}$ Nieves Sánchez (ed.), Tratados de la peste, Madrid, Arco/Libros, pp. 77-158.

Gordonio, Bernardo de (1993): Lilio de medicina, Brian Dutton y M. ${ }^{a}$ Nieves Sánchez (eds.), 2 vols., Madrid, Arco/Libros.

Granado, Diego (1599): Libro del arte de cozina [...], Madrid, Luis Sánchez.

Herrera = Capuano, Thomas (1995 [1513]): Texto y concordancias de la Obra de agricultura de Gabriel Alonso de Herrera, Madison, Seminary of Medieval Studies.

La Torre, Alfonso de (1991): Visión deleytable, Jorge García López (ed.), Salamanca, Universidad de Salamanca.

Lobera de Ávila, Luis (2013 [1530]): Vanquete de nobles cavalleros e modo de bivir desde que se leuantan hasta que se acuestan [...], Augsburg, <http://hdl.handle.net/11169/901> .

Lozana $=$ Delicado, Francisco (2011): La Lozana Andaluza, Jesús Sepúlveda y Carla Perugini (eds.), Málaga, Universidad de Málaga.

Maceras = Hernández de Maceras, Domingo (1999 [1607]): Libro del arte de cozina, Santiago Gómez Laguna (ed.), Salamanca, Universidad de Salamanca.

MMugeres = Martínez Crespo, Alicia (ed.) (1995): Manual de mugeres en el qual se contienen muchas y diversas reçeutas muy buenas, Salamanca, Universidad de Salamanca.

Montiño = Martínez Mo[n]tiño, Francisco (2009 [1611]): Arte de cozina, pastelería, vizcochería, y conseruería, Madrid, Luis Sánchez. <http://books.google.es/books?id=tVMQ2Dsmv-8C\&>.

Nebrija, Elio Antonio de (1989 [¿1595?]): Vocabulario español-latino, reimpresión de la reproducción facsímil de la RAE de 1951, Madrid, Real Academia Española.

Nola, Ruperto de (1529): Libro de guisados, manjares y potajes intitulado Libro de cozina [...], Logroño, Miguel de Eguía. <http://es.scribd.com/doc/45095908/Libro-de-Guisados-Ruperto-Nola>.

Palencia $=$ Fernández de Palencia, Alfonso (1967): Universal vocabulario en latín y en romance, reproducción facsímil de la ed. de 1490, nota preliminar de S. Gili Gaya, 2 vols., Madrid, Comisión Permanente de la Asociación de Academias de la Lengua Española, <http:// www.cervantesvirtual.com/obra-visor/universal-vocabulario-en-latin-y-en-romance-tomo-i-0/ html/> y <http://www.cervantesvirtual.com/nd/ark:/59851/bmc0c4t6>.

Quijote $=$ Cervantes, Miguel de (1999): Don Quijote de la Mancha, Instituto Cervantes (ed.), Francisco Rico (dir.), Joaquín Forradellas (col.), Fernando Lázaro Carreter (estudio preliminar), 3. ${ }^{a}$ ed., 2 vols., Barcelona, Crítica.

Ribera, Suero de (1991): "Poema sobre la conducta del perfecto galán”, en Álvaro Alonso (ed.), Poesía de cancionero, Madrid, Cátedra, pp. 197-198.

Rueda, Lope de (1981): "La tierra de Jauja”, en Fernando González Ollé y Vicente Tusón (eds.), Pasos, Madrid, Cátedra.

Scappi, Bartolomeo (1570): Opera, Venetia, Michele Tramezzino. <http://books.google.ch/ books?id=9VCtiKCegTUC $\&$ printsec $=$ frontcover $\& \mathrm{hl}=\mathrm{de} \# \mathrm{v}=$ onepage $\& \mathrm{q} \& \mathrm{f}=\mathrm{false}>$.

Sevillana medicina = Aviñón, Juan de (2000): Sevillana medicina, José Mondéjar (ed.), Madrid, Arco/Libros.

Talavera $=$ Teresa de Castro (2001): "El Tratado sobre el vestir, calzar y comer del arzobispo Hernando de Talavera", Espacio, tiempo y forma. Serie III, Historia medieval, 14, pp. 11-92.

Torquemada, Antonio de (1994): "Coloquio que trata de la desorden que en este tiempo se tiene en el mundo, y principalmente en la christiandad, en el comer y beber, [...]", en Obras completas, I, Madrid, Turner, pp. 325-340. 
TrPatología = Tratado de patología (1997): M. ${ }^{a}$ Teresa Herrera y M. ${ }^{a}$ Nieves Sánchez (eds.), Madrid, Arco/Libros.

Vallés, Juan (2008): Regalo de la vida humana, Fernando Serrano Larráyoz (ed.), Pamplona/ Wien, Gobierno de Navarra/Oesterreichische Nationalbibliothek.

Villena, Enrique de (1984): Arte cisoria, Russell V. Brown (ed.), Barcelona, Editorial Humanitas.

\section{BIBLIOGRAFÍA}

Autoridades = Real Academia Española (1979 [1726-1739]): Diccionario de autoridades, edición facsímil, 3 vols., Madrid, Gredos.

Blank, Andreas (1997): Prinzipien des lexikalischen Bedeutungswandels am Beispiel der romanischen Sprachen, Tübingen, Niemeyer.

Carnevale Schianca, Enrico (2011): La cucina medievale. Lessico, storia, preparazioni, Firenze, Leo S. Olschki Editore.

Castro Martínez, Teresa de (1996): La alimentación en las crónicas castellanas bajomedievales, Granada, Universidad de Granada.

Castro Martínez, Teresa de (2002): "L'émergence d'une identité alimentaire: Musulmans et chrétiens dans le royaume de Grenade", en Martin Bruegel y Bruno Laurioux (dirs.), Histoire et identités alimentaires en Europe, Paris, Hachette, pp. 199-215.

Ciceri, Marcella (1992): "La berenjena: un cibo connotante", en Maria Grazia Profeti (ed.), Codici del gusto, Milano, Francoangeli, pp. 87-94.

Colson, Maryse (2014): Étude linguistique du "Cuisinier françois" de La Varenne (1615). Le vocabulaire culinaire comme système, la recette de cuisine comme genre, Saarbrücken, Éditions Universitaires Européennes.

CORDE = Real Academia Española: Corpus diacrónico del español (CORDE), <http:// www.rae.es> [fecha de consulta: febrero de 2014].

CREA = Real Academia Española: Corpus de referencia del español actual (CREA), <http:// www.rae.es> [fecha de consulta: febrero de 2014].

Cruz Volio, Gabriela (2012): "La función ideacional del lenguaje en las recetas de Apicio", Káñina. Revista de Artes y Letras, 36.2, pp. 153-169.

DCECH = Corominas, Joan y José A. Pascual (1980-1991): Diccionario crítico etimológico castellano e hispánico, 6 vols. Madrid, Gredos.

$D E A=$ Seco, Manuel, Olimpia Andrés y Gabino Ramos (1999): Diccionario del español actual, 2 vols., Madrid, Aguilar.

DECLlC = Coromines, Joan (1980-1991): Diccionari etimològic $i$ complementari de la llengua catalana, 9 vols., Barcelona, Curial / La Caixa.

$D E M=$ Müller, Bodo (1987- ): Diccionario del español medieval, Heidelberg, Winter.

DRAE 2014 = Real Academia Española (2001): Diccionario de la lengua española, 23. ${ }^{a}$ ed., Madrid, Espasa.

Eberenz, Rolf (2012): "Cuando la comida y la bebida no se llamaban así: exploración de un área semántica del castellano medieval”, en Yvette Bürki, Manuela Cimeli y Rosa Sánchez (coords.), Lengua, Llengua, Llingua, Lingua, Langue. Encuentros filológicos (ibero)románicos. Estudios en homenaje a la Profesora Beatrice Schmid, München, Peniope-Verlag Anja Urbanek, pp. 203-214.

Eberenz, Rolf (2014a): "El léxico español de la alimentación y la culinaria en su historia: fuentes y líneas de investigación”, en Vicente Álvarez Vives, Elena Díez del Corral Areta y Natacha Reynaud Oudot (coords.), Dándole cuerda al reloj: ampliando perspectivas en lingüística histórica del español, Valencia, Tirant Humanidades, pp. 23-46.

Eberenz, Rolf (2014b): "Alimentos, platos y bebidas en el Tesoro de la lengua castellana o española (1611) de Sebastián de Covarrubias”, en Rolf Eberenz (ed.), Discursos hispánicos sobre 
alimentación y culinaria. Aproximaciones literarias y lingüísticas, Madrid, Visor Libros, pp. 385-407.

Gemmingen, Barbara von (1987): "Das verborgene Kochbuch des Herrn Oudin oder: Untersuchungen zum kulinarischen Wortschatz im zweisprachigen Wörterbuch", Zeitschrift für Romanische Philologie, 103, pp. 491-499.

Gómez García, Pedro (1993): "Lo crudo, lo cocido y lo podrido: de las estructuras mitológicas a las culinarias", Anthropologica. Revista de etnopsicología y etnopsiquiatría, 13-14, pp. 93-111.

Grewe, Rudolf (1979): "Introducció", en Libre de Sent Soví (receptari de cuina), Rudolf Grewe (ed.), Barcelona, Barcino, pp. 7-60.

Guerreau-Jalabert, Anita (1992): "Aliments symboliques et symbolique de la table dans le roman arthurien (XIIe-XIIIe siècles)”, Annales. Économies, Sociétés, Civilisations, 47.3, pp. 561-594.

Gunzberg Moll, Jordi (1995): "La alimentación en los tratados de preservación y curación de la peste”, en Actes Ir Col.loqui d'Història de l'Alimentació a la Corona d'Aragó. Edat Mitjana, Lleida, Institut d'Estudis Ilerdencs, vol. 2, pp. 857-869.

Joly, Monique (1990): "L'idéologie de la poule au pot: les avatars de la olla podrida", en A. Redondo (ed.), Le corps dans la société espagnole des XVIe et XVIIe siècles, Paris, Publications de la Sorbonne, pp. 103-112.

Lehrer, Adrienne (1969): "Semantic cuisine", Journal of Linguistics, 5, pp. 39-55.

Lehrer, Adrienne (1972): "Cooking Vocabularies and the Culinary Triangle of Lévi-Strauss", Anthropological Linguistics, 14.5, pp. 155-171.

Levi-Strauss, Claude (1968): Mythologiques. L'origine des manières de table, Paris, Plon.

Lévi-Strauss, Claude (1978 [1964]): Le cru et le cuit, Paris, Plon.

Lévi-Strauss, Claude (2004 [1965]): "Le triangle culinaire", Food \& History, 2, pp. 9-19.

Mühlethaler, Jean-Claude (1996): "De la frugalité de l'ermite au faste du prince: les codes alimentaires dans la littérature médiévale", en Manger: cours public de l'Université, 1995 1996, Lausanne, Payot, pp. 7-35.

Pérez Samper, M. ${ }^{a}$ Ángeles (2000-2001): "Estilo de servir a príncipes. La cocina y la mesa de un grande de España en el Siglo de Oro", Trocadero. Revista de historia moderna y contemporánea, 12-13, pp. 315-360.

Peyrebonne, Nathalie (1997): La table et les aliments dans les dialogues et le théâtre du XVI siècle espagnol, Lille, Atelier National de Reproduction des Thèses.

Plaza Picón, Francisca del Mar (2012): "Los verbos de cocinar en el De re coquinaria. Transfor-

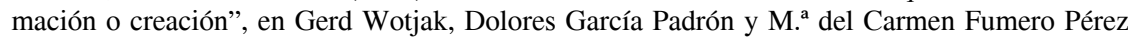
(eds.), Estudios sobre lengua, cultura y cognición, Bern, Peter Lang, pp. 207-214.

Rothe, Arnold (1982): “Comer y beber en la obra de Quevedo", en James Iffland (ed.), Quevedo in Perspective: Eleven Essays for the Quadricentennial. Proceedings from the Boston Quevedo Symposium, October, 1980, Newark, Juan de la Cuesta, pp. 181-225.

Trias Mercant, Sebastià (1995): "La cuina lul.liana. Criteris dialèctics i nivells socials", Actes Ir Col.loqui d'Història de l'Alimentació a la Corona d'Aragó. Edat Mitjana, Lleida, Institut d'Estudis Ilerdencs, vol. 2, pp. 845-856.

Wotjak, Gerd (1992): "Acerca del potencial comunicativo de las unidades léxicas o qué se tiene al pedir vianda(s)", en Elizabeth Luna Traill (coord.), Scripta philologica in honorem Juan M. Lope Blanch, a los 40 años de docencia en la UNAM y a los 65 años de vida, México, UNAM, vol. 2, pp. 257-271.

Fecha de recepción: 6 de abril de 2014

Fecha de aceptación: 19 de septiembre de 2014 